\title{
Relationship of insulin resistance to microvascular dysfunction in subjects with fasting hyperglycaemia
}

\author{
A .J.J aap, A . C . Shore, J . E .Tooke \\ D epartment of D iabetes and Vascular M edicine, Postgraduate M edical School, U niversity of E xeter, E xeter, U K
}

Summary Microvascular hyperaemia is decreased in subjects at risk of developing non-insulin-dependent diabetes mellitus (NIDDM) who have fasting hyperglycaemia. Such microvascular abnormalities may be involved in the pathogenesis of diabetic microangiopathy. To investigate the relationship of reduced microvascular hyperaemia to metabolic and blood pressure abnormalities associated with the prediabetic state, we studied 24 subjects with fasting hyperglycaemia and 24 age- and sex-matched control subjects. The microvascular hyperaemic response to local heating of the skin on the dorsum of the foot measured by laser Doppler fluximetry was reduced in the subjects with fasting hyperglycaemia (1.18 [0.871.83 ] volts vs 1.51 [1.30-2.14] volts normal subjects; $p=0.0002$ ) and was negatively correlated with fasting plasma insulin concentration $\left(R_{s}=-0.70 ; p=0.001\right)$ and positively related to insulin sensitivity determined by continuous infusion of glucose with model assessment (CIGMA) $\quad\left(R_{s}=0.52 ; p=0.01\right)$, but showed no association with fasting plasma glucose, beta-cell function, $24 \mathrm{~h}$ ambulatory blood pressure profiles or serum lipid concentrations. These results suggest that hyperinsulinaemia, as a result of insulin resistance, may have a detrimental effect on microvascular function in the prediabetic state. [Diabetologia (1997) 40: 238-243]

Keywords Non-insulin-dependent diabetes mellitus, impaired glucose tolerance, microcirculation, blood flow, insulin resistance.
The development of diabetic microvascular complications may be the end result of longstanding functional abnormalities in the microcirculation such as altered capillary pressure, blood flow and permeability, which are present from an early stage in the course of diabetes mellitus [1-3]. There is now abundant evidence in support of this concept in patients with insulin-dependent diabetes (ID D M ) [1-4] and also accumulating evidence of early functional microvascular changes in patients with non-insulin-dependent

R eceived: 24 J une 1996 and in final revised form: 11 N ovember 1996

Corresponding author: D r. A .Jaap, D iabetes Centre, R oyal Infirmary, 84 Castle Street, G lasgow G 4 OSF, U K

A bbreviations: NID D M, N on-insulin-dependent diabetes mellitus; IG T, impaired glucose tolerance; CIG M A , continuous infusion of glucose with model assessment; IDDM, insulin-dependent diabetes mellitus. diabetes (NID D M ) [5]. The pattern of abnormalities, however, appears to differ between the two main types of diabetes, paralleling known differences in the epidemiology of microvascular disease, e.g. the higher prevalence of proliferative retinopathy in IDDM patients and of maculopathy in NIDDM patients [5]. The major microvascular functional abnormality found in the skin of normotensive patients with NIDDM is a profound reduction in hyperaemic responses [6, 7]; whereas capillary pressure [8] and capillary filtration coefficient [9] (a measure of fluid permeability) appear to be normal. Like established microvascular disease, e. g. retinopathy [10], reduced microvascular hyperaemia may already be present at the time of diagnosis in NIDDM [7]. This does not seem to relate to a long period of unrecognised diabetes as a similar reduction in hyperaemic response has been demonstrated in subjects with fasting hyperglycaemia at high risk of developing NIDDM [11]. A s 
these subjects only had minimal hyperglycaemia (fasting plasma glucose level $5.5-7.8 \mathrm{mmol} / \mathrm{l}$ ), this suggests that other metabolic abnormalities associated with the prediabetic state, such as insulin resistance, may play a role in the pathogenesis of microvascular dysfunction in subjects with impaired glucose tolerance (IG T). This hypothesis is supported by the results of in vitro studies showing proliferation of microvascular cells in culture on exposure to insulin [12]. A Iternatively, microvascular dysfunction in IGT subjects who are normotensive on clinic measurements could relate to an abnormal 24-h blood pressure profile: an altered diurnal rhythm in blood pressure has been found on 24-h ambulatory monitoring in some normotensive NIDDM patients and has been related to the presence of microvascular complications [13].

The aim of this study, therefore, was to investigate the relationship of reduced microvascular hyperaemia to metabolic and blood pressure abnormalities associated with the prediabetic state.

\section{Subjects and methods}

Subjects. We studied 24 subjects with fasting hyperglycaemia (Table 1) who were recruited consecutively on entry to the Exeter cohort of the Fasting $\mathrm{H}$ yperglycaemia Study, a multicentre, prospective, randomised study comparing the effects on IGT of diet and exercise, with or without sulphonylurea treatment. This group had been recruited from a high-risk population who all had one or more risk factors for the development of NIDDM (affected first degree relative, previous gestational diabetes, obesity, known IG T). A II had a fasting venous plasma glucose concentration between 5.5 and $7.8 \mathrm{mmol} / \mathrm{l}$ (i.e. greater than the 95th centile for the normal population and lower than the World $\mathrm{H}$ ealth O rganisation (WH O) definition for diabetes [14] ) on two occasions prior to entry to the study. We recruited 24 healthy age- and sex-matched control with no family history of diabetes from hospital staff, patients' friends and spouses, and local advertisements (Table 1 ).

A s hypertension and large vessel disease may independently affect microvascular flow measurements $[15,16]$, subjects were only included if they were normotensive (brachial blood pressure $<160 / 90 \mathrm{mmHg}$ ), and if they had no evidence of large vessel disease (as determined by a history suggestive of ischaemic heart disease, peripheral vascular disease or cerebral ischaemia; diminished lower limb pulses or ankle to brachial systolic pressure index $<1.0$ ). No subjects were taking any potentially vasoactive medications and all had a normal serum creatinine concentration. The study protocol was approved by the local research ethics committee and informed verbal consent was obtained from all participants.

There were three cigarette smokers and four ex-smokers among the subjects with hyperglycaemia, and three smokers and one ex-smoker in the control group. None of the subjects with fasting hyperglycaemia had retinopathy as determined by a combination of ophthalmoscopy through dilated pupils and retinal photography [10]; two had microalbuminuria (urinary albumin [mg/l]: creatinine [mmol/l] ratio $>3.5$ in an early morning urine sample, in the absence of urinary tract infection); and two had significant large-fibre neuropathy
Table 1. Characteristics of subjects with fasting hyperglycaemia and control subjects

\begin{tabular}{|c|c|c|c|}
\hline & $\begin{array}{l}\text { Fasting } \\
\text { hyperglycaemia }\end{array}$ & Control & $p$ values \\
\hline n (male/female) & $13 / 11$ & $13 / 11$ & \\
\hline A ge (years) & $46.5(36-64)$ & $50.0(32-66)$ & 0.56 \\
\hline $\mathrm{BM} I\left(\mathrm{~kg} / \mathrm{m}^{2}\right)$ & $28(22-34)$ & $26(19-32)$ & 0.08 \\
\hline Glucose (mmol/l) & $5.8(4.8-7.1)$ & $4.4(3.2-5.4)$ & 0.0001 \\
\hline $\mathrm{HbA}_{1 \mathrm{c}}(\%)$ & $5.7(5.0-7.3)$ & & \\
\hline $\begin{array}{l}\text { Total cholesterol } \\
(\mathrm{mmol} / \mathrm{l})\end{array}$ & $4.98(3.31-7.83)$ & $4.35(3.22-5.82)$ & 0.42 \\
\hline $\begin{array}{l}\text { HDL cholesterol } \\
(\mathrm{mmol} / \mathrm{l})\end{array}$ & 1.09 (0.77-1.98) & & \\
\hline $\begin{array}{l}\text { LDL cholesterol } \\
(\mathrm{mmol} / \mathrm{l})\end{array}$ & $3.10(1.45-4.77)$ & & \\
\hline $\begin{array}{l}\text { Triglycerides } \\
(\mathrm{mmol} / \mathrm{l})\end{array}$ & $1.06(0.46-5.48)$ & $1.14(0.53-2.89)$ & 0.33 \\
\hline $\begin{array}{l}\text { Systolic blood } \\
\text { pressure (mm Hg) }\end{array}$ & $123(97-146)$ & $129(102-148)$ & 0.10 \\
\hline $\begin{array}{l}\text { Diastolic blood } \\
\text { pressure (mm H g) }\end{array}$ & $70.5(51-83)$ & $72.0(63-88)$ & 0.33 \\
\hline
\end{tabular}

$\mathrm{D}$ ata are shown as median and (range)

(vibration perception threshold on the great toes greater than the age-adjusted 95th centile for a normal population), determined using a Biothesiometer (Biomedical Instrument Co., N ewbury, O hio, USA ) [17].

\section{M ethods}

A II measures were made in each subject within a 10-day period.

$M$ easurement of insulin sensitivity and beta-cell function. Insulin sensitivity and beta-cell function were measured using the technique of continuous infusion of glucose with model assessment (CIGMA) [18] which employs a low-dose intravenous glucose infusion with measurement of glucose, insulin and Cpeptide levels during the infusion, and mathematical modelling of the results. Derived values for insulin sensitivity and beta-cell function are comparable to those obtained from the more complex euglycaemic hyperinsulinaemic, and hyperglycaemic clamp methods [18, 19].

The CIGMA study was carried out on each subject following an overnight fast. Basal values for plasma glucose, C-peptide and insulin were determined from the mean of three samples taken at 5-min intervals before an infusion of $10 \%$ dextrose solution at a dose of $5 \mathrm{mg} \cdot \mathrm{kg}$ ideal body weight ${ }^{-1}$. $\mathrm{min}^{-1}$ over $60 \mathrm{~min}$, with further blood samples taken during the infusion for measurement of glucose, $\mathrm{C}$-peptide and insulin at 50,55 and $60 \mathrm{~min}$. Blood samples were collected from an indwelling venous cannula in the forearm which was flushed with $0.9 \% \mathrm{NaCl}$ between samples, a heating blanket around the forearm ensuring arterialisation of venous blood prior to sampling. Plasma insulin was measured using a sensitive two-site ELISA method [20] and C-peptide by radioimmunoassay [21]. CIGMA data for beta-cell function and insulin sensitivity were then derived from the plasma glucose, Cpeptide and insulin concentrations using computer-based mathematical modelling [18], with results expressed as a percentage of predicted normal values. Basal blood samples 
were also collected to measure fasting serum lipids and $\mathrm{HbA}$ 1c (high performance liquid chromatography; normal range 4.3$6.1 \%)[21]$.

A mbulatory blood pressure monitoring. We carried out 24-h ambulatory blood pressure monitoring on a separate occasion. Recordings were made on the left arm using a Takeda TM 2420 device (A \& D Engineering Inc., M ilpitas, Calif., U SA ). A fter careful positioning and taping of the blood pressure cuff and tubing, three test readings were taken using the TM - 2420 and compared with three simultaneous readings from the right arm using an automated device (Takeda UA -751, A \& D E ngineering Inc). The positioning was deemed satisfactory if both systolic and diastolic blood pressure differed by less than $5 \mathrm{~mm} \mathrm{H} \mathrm{g}$ between the two devices [22]. This procedure was repeated at the end of the 24-h recording to check the reliability of the data, which was only accepted if the difference between the two devices remained less than $5 \mathrm{~mm} \mathrm{H}$ g. Subjects kept a diary in which they recorded their daily activities including time of going to sleep and wakening. M ean 24-h blood pressure and mean daytime (i.e. during waking hours) and nocturnal (i.e. during sleep) blood pressures were calculated for each subject.

Microvascular hyperaemia. A t a final visit microvascular hyperaemia was measured using the following protocol. Subjects were asked to refrain from smoking and taking caffeine-containing drinks on the day of the study. Prior to blood flow measurements, subjects were allowed to acclimatise for $30 \mathrm{~min}$ at $22 \pm 0.5^{\circ} \mathrm{C}$ in a controlled temperature laboratory. $\mathrm{D}$ uring this time an area of skin on the dorsum of the right foot was heated to $44^{\circ} \mathrm{C}$ with a small brass heater attached to the skin surface [23]. H eating the skin to this temperature has been shown to induce maximum vasodilation [23, 24]. The maximum microvascular hyperaemic response was determined by laser D oppler fluximetry (Periflux Pf2; Perimed, Stockholm, Sweden) and taken as the mean flow (expressed arbitrarily in volts [V ]) in eight equidistant sites in the heated area [23]. We have previously found this technique to be reproducible with a mean intra-subject coefficient of variation of $8.9 \%$ [25].

Statistical analysis. $D$ ata are presented as median and range as they were not normally distributed. Comparisons between groups were made using the M ann-Whitney $\mathrm{U}$ test and associations between variables by determination of Spearman $R$ ank correlation coefficients $\left(R_{s}\right)$. The independent contribution of different variables to maximum hyperaemia was assessed by multiple logistic regression analysis. All statistics were performed on a microcomputer using the SPSS/PC + statistical package (SPSS Inc., Chicago, III., USA ).

\section{Results}

There was a significant reduction in maximum microvascular hyperaemia in the subjects with fasting hyperglycaemia (1.18 [0.87-1.83] V vs 1.51 [1.302.14] V normal subjects; $p=0.0002$ ) (Fig. 1), confirming the results of our previous study [11]. A wide spectrum of values was observed for insulin sensitivity and beta-cell function in the fasting hyperglycaemia group (Table 2), with microvascular hyperaemia being negatively correlated with fasting plasma insulin concentration $\left(R_{s}=-0.70 ; p=0.001\right)$ (Fig. 2$)$, and

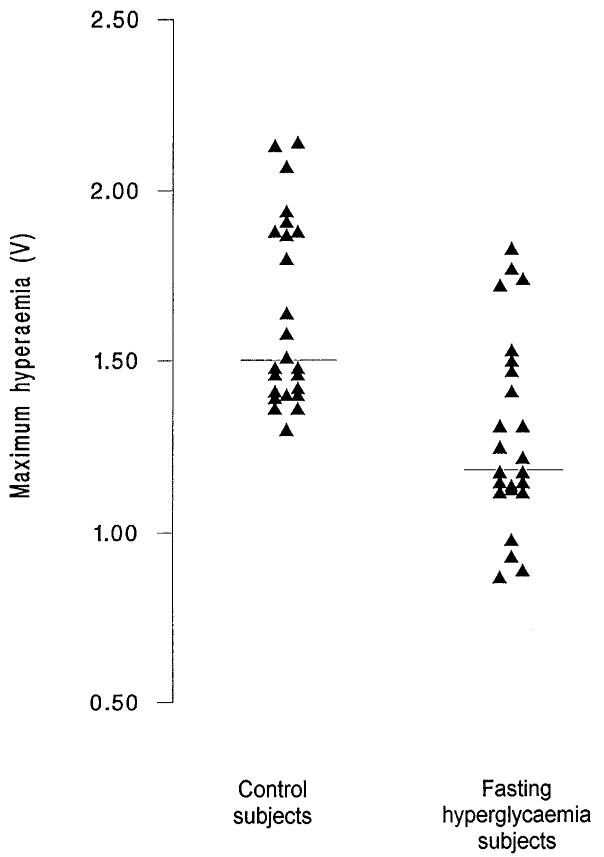

Fig. 1. M aximum microvascular hyperaemia in subjects with fasting hyperglycaemia and control subjects (horizontal bars represent median values)

Table 2. I nsulin sensitivity, beta-cell function and 24-h ambulatory blood pressure in subjects with fasting hyperglycaemia

\begin{tabular}{ll}
\hline Fasting plasma insulin (pmol/l) & $55.8(27.6-115.8)$ \\
Insulin sensitivity $(\%)$ & $80.7(19.5-178.8)$ \\
Beta-cell function (\%) & $87.1(38.5-169.4)$ \\
M ean daytime blood pressure $(\mathrm{mm} \mathrm{H} \mathrm{g})$ & $97.3(81.6-110.2)$ \\
M ean nocturnal blood pressure $(\mathrm{mm} \mathrm{H} \mathrm{g})$ & $77.1(67.2-97.3)$
\end{tabular}

$\mathrm{D}$ ata are shown as median and (range)

positively correlated with insulin sensitivity $\left(R_{s}=0.52 ; p=0.01\right)$ (Fig. 3$)$. In contrast, there was no association of maximum hyperaemia with betacell function $(p=0.50), \mathrm{HbA}_{1 c}(p=0.11)$, or fasting plasma glucose concentration ( $p=0.83$ ). M ultiple regression analysis with maximum hyperaemia as the dependent variable confirmed a significant relationship between limited vasodilation and fasting insulin level $(t=-4.53, p=0.0002)$, whereas insulin sensitivity no longer showed a significant association $(t=1.02, p=0.32)$, probably as a result of the relationship between fasting plasma insulin and insulin sensitivity $\left(R_{s}=-0.56, p=0.03\right)$.

There wasno association between maximum hyperaemia and age $(p=0.31)$ or markers of abdominal obesity (waist-hip ratio [ $p=0.91]$ and body massindex $[p=0.95]$ ). The majority of subjects with fasting hyperglycaemia had normal lipid profiles (Table 1) and there was no correlation between maximum hyperaemia and serum lipid concentrations ( $p=0.11$ for total cholesterol; $p=0.51$ for HDL cholesterol; $p=0.12$ for LDL cholesterol; and $p=0.78$ for triglycerides). 


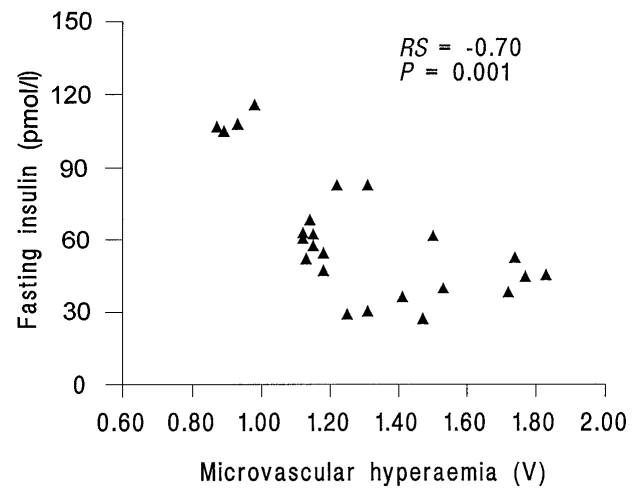

Fig. 2. Correlation between maximum hyperaemia and fasting plasma insulin concentration in subjects with fasting hyperglycaemia

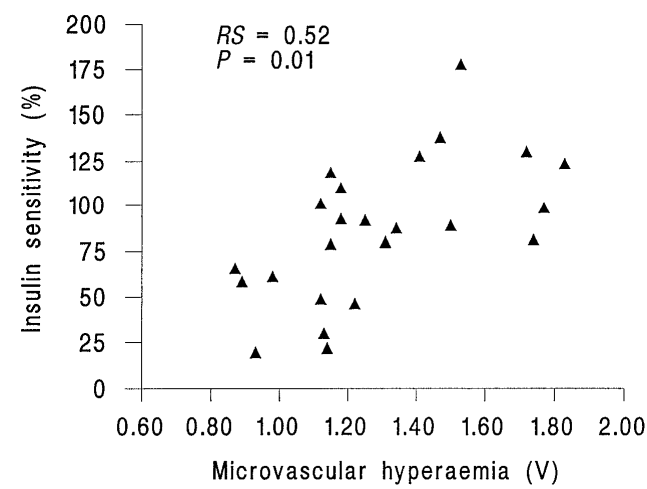

Fig. 3. Correlation between maximum hyperaemia and insulin sensitivity in subjects with fasting hyperglycaemia

N one of the group with fasting hyperglycaemia had undetected hypertension on 24-h ambulatory monitoring and all had a normal diurnal rhythm for arterial pressure, with lower values during sleep (Table 2). There was no association between these blood pressure parameters and maximum hyperaemia.

\section{Discussion}

This study has confirmed, in a different population, our previous observation of reduced microvascular hyperaemia in subjects at risk of developing N ID D M who have fasting hyperglycaemia [11], and further explored the interactions of features of the insulin resistance syndrome with microvascular function. Fasting plasma insulin concentration and insulin sensitivity were associated with reduced microvascular hyperaemia. In contrast there was no relationship between beta-cell function and limited vasodilation.

It seems unlikely that the limited microvascular hyperaemia is due to undetected atherosclerosis in upstream larger vessels as all subjects included in the study had normal foot pulses and ankle: brachial pressure index. There was little evidence that other features associated with the insulin resistance state had any relationship to impaired microvascular function. There was no evidence of undetected hypertension or loss of diurnal rhythm of arterial pressure on 24-h ambulatory monitoring, and no association between parameters relating to the 24-h recording and limited vasodilation. Plasma glucose concentration was only slightly elevated in the subjects with IGT, and was below optimal treatment levels proposed for both IDDM [26] and NIDDM [27]; levels which have been shown to significantly reduce microvascular complications, at least in IDDM patients [26]. In view of this and also the lack of association with reduced microvascular hyperaemia in the current study, plasma glucose concentration would not seem to be a major determinant of limited vasodilation in prediabetic subjects with fasting hyperglycaemia. Similarly, there was no association between serum lipid levels and reduced hyperaemia, although as only a few subjects had elevated cholesterol or triglyceride levels, this would not preclude a role for hyperlipidaemia in other insulin resistant groups. Indeed, there is evidence of impaired endothelium-dependent vasodilation in larger vessels in patients with hypercholesterolaemia, which is reversed by a reduction in LDLcholesterol levels [28], and similar abnormalities are found in the presence of raised non-esterified fatty acid levels [29].

The subjects with IG T tended to be overweight; however, in this study there was no association of limited vasodilation with body mass index or waist-hip ratio. It is interesting to note that more marked obesity has been associated with endothelial dysfunction in other studies and that this has been linked to insulin resistance [30]. In healthy control subjects insulin has a physiological vasodilator action in skeletal muscle [31], which appears to be important both for the maintenance of vascular tone and modulation of glucose uptake. The vasodilator effect of insulin is mediated by endothelium-derived nitric oxide through increases in cyclic nucleotides [31, 32]. Insulin resistant states have been associated with both defective insulin-mediated vasodilation [33] and endothelium-dependent vasodilation [34], suggesting the presence of 'vascular insulin resistance'. This effect seems to be independent of associated hypertension, hyperlipidaemia and hyperglycaemia [30].

0 ur results suggest that insulin resistance or associated metabolic effects such as hyperinsulinaemia may have a similar detrimental effect on microvascular cell function in subjects at risk of diabetes, although unfortunately we did not assess insulin sensitivity in the control group. A ny effect of insulin on microvascular vasodilation would appear to require chronic exposure, as preliminary work has shown hyperaemic responses to remain unchanged during euglycaemic hyperinsulinaemic clamp studies in healthy volunteers (unpublished observations). The 
mechanisms of this 'microvascular insulin resistance' remain to be elucidated. D efective endothelium-dependent and independent microvascular vasodilation has been found in patients with NID D M [35]. H yperinsulinaemia has also been associated with increased circulating levels of endothelin-1 [36], although vascular responses to this vasoconstrictor may be reduced in NIDDM patients [37]. Finally, it is possible that limited vasodilation may relate to insulin-induced microvascular smooth muscle cell proliferation, possibly related to reduced levels of endothelium-derived nitric oxide, paralleling the effects observed in cell culture experiments [12, 38].

In conclusion, the reduced microvascular vasodilation found in subjects at risk of developing diabetes, who have IG T is associated with fasting hyperinsulinaemia and insulin resistance.

A cknowledgements. This study was made possible by support from the Wellcome Trust (grant no.032627/1.27). The Fasting $\mathrm{H}$ yperglycaemia Study is supported by Servier Laboratories $\mathrm{L}$ td. We thank D r. S. M anly and the Fasting H yperglycaemia Study for supplying data on insulin, insulin sensitivity, betacell function, lipids and $\mathrm{HbA}{ }_{1 c}$. The authors gratefully acknowledge the expert technical assistance of M S. J. Stockman in collecting 24-h ambulatory blood pressure data.

\section{References}

1. Parving $\mathrm{H}-\mathrm{H}$, V iberti G C, K een $\mathrm{H}$, Christiansen J $\mathrm{S}$, L assen NA (1983) Haemodynamic factors in the genesis of diabetic microangiopathy. M etabolism 32: 943-949

2. Zatz R, B renner BM (1986) Pathogenesis of diabetic microangiopathy: the haemodynamic view. A m J Med 80: 443-453

3. Tooke JE (1986) M icrovascular haemodynamics in diabetes mellitus. Clin Sci 70: 119-125

4. Sandeman DD, Shore A C, Tooke JE (1992) Relation of skin capillary pressure in patients with insulin-dependent diabetes to complications and metabolic control. N E ngl J M ed 327: 760-764

5. Jaap AJ, Tooke JE (1995) The pathophysiology of microvascular disease in type 2 diabetes. Clin Sci 89: 3-12

6. Tur E, Yosipovitch G, Bar-On Y (1991) Skin reactive hyperaemia in diabetic patients. A study by laser Doppler flowmetry. D iabetes Care 14: 958-962

7. Sandeman D D, Pym C, G reen E M, Seamark C, Shore A C, Tooke JE (1991) M icrovascular vasodilation in feet of newly diagnosed non-insulin dependent diabetic patients. B M J 302: 1122-1123

8. Shore A C, Jaap A J, Tooke JE (1994) Capillary pressure in patients with NIDD M. D iabetes 43: 1198-1202

9. Jaap AJ, Shore A C, Gamble J, G artside IB, Tooke JE (1994) Capillary filtration coefficient in type 2 (non-insulin-dependent) diabetes. J Diab Comp 8: 111-116

10. U K Prospective D iabetes Study 6 (1990) Complications in newly diagnosed type 2 diabetic patients and their associations with different clinical and biochemical risk factors. Diabetes R es 13: 1-11

11. Jaap A J, H ammersley MS, Shore A C, Tooke JE (1994) Reduced microvascular hyperaemia in subjects at risk of developing type 2 (non-insulin-dependent) diabetes. Diabetologia 37: 214-216

12. K ing GL, Goodman A D, Buzney S, Moses A, Kahn CR (1985) R eceptor and growth-promoting effects of insulin and insulinlike growth factors on cells from bovine retinal capillaries and aorta. J Clin Invest 75: 1028-1036

13. Nakano S, U chida K, K igoshi T, et al. (1991) Circadian rhythm of blood pressure in normotensive NIDDM subjects. I ts relationship to microvascular complications. Diabetes Care 14: 707-711

14. WHO Study Group (1990) Report on diabetes mellitus. World Health Organisation, Technical Report Series 727, G eneva

15. Jaap A J, Shore A C, Tooke JE (1994) The influence of hypertension on microvascular blood flow and resistance to flow in the skin of patients with non-insulin-dependent diabetes. D iabet M ed 11: 883-887

16. U bbink DT, Jacobs M J, Slaaf DW, Tengelder GJ, R eneman R S (1992) M icrovascular reactivity differences between the two legs of patients with unilateral lower limb ischaemia. E ur J Vasc Surg 6: 269-275

17. Wiles PJ, Pearce SM , R ice PJ S, M itchell J M O (1991) Vibration perception threshold: influence of age, height, sex and smoking, and calculation of accurate centile values. D iabet M ed 8: 157-161

18. H osker J P, M atthews D R, R udenski A S, B urnett M A, D arling P, B own E G, Turner R C (1985) Continuous infusion of glucose with model assessment: measurement of insulin sensitivity and beta-cell function in man. Diabetologia 28: 401-411

19. L evy J C, R udenski A , B urnett $M$, K night $R$, M atthews D R, Turner R C (1991) Simple empirical assessment of beta-cell function by a constant infusion of glucose test in normal and type 2 (non-insulin-dependent) diabetic subjects. Diabetologia 34: 488-499

20. A ndersen $L$, D inesen $B$, J ørgensen $P N$, Poulsen $F, R ø d e r$ ME (1992) E nzyme immunoassay for intact human insulin in serum or plasma. Clin Chem 39: $578-582$

21. U K Prospective Diabetes Study Group (1994) UK Prospective Diabetes Study (UKPDS) XI. Biochemical risk factors in type 2 diabetic patients at diagnosis compared with age-matched normal subjects. Diabet M ed 11: 534-544

22. White W B (1991) A ssessment of ambulatory blood pressure recorders: accuracy and clinical performance. Clin Invest $M$ ed 14: 202-211

23. R ayman G, Williams SA, Spencer PD, Smaje L H, Wise PH , Tooke JE (1986) Impaired microvascular hyperaemic response to minor skin trauma in type 1 diabetes. BM J 292: 1295- 1298

24. Johnson J M , O 'L eary DS, Taylor WF, Kosiba W (1986) E ffect of local heating and cooling on forearm reactive hyperaemia. Clin Physiol 6: 337-346

25. Jaap A J, Pym CA, Seamark C, Shore A C, Tooke JE (1995) $M$ icrovascular function in type 2 (non-insulin-dependent) diabetes: improved vasodilation after one year of good glycaemic control. D iabet M ed 12: 1086-1091

26. D iabetes $C$ ontrol and Complications Trial $R$ esearch $G$ roup (1993) The effect of intensive treatment on the development and progression of long-term complications in insulin-dependent diabetes mellitus. N Engl J Med 329: 977986

27. A lberti K G M M, Gries FA, Jervell J, Krans HJ (1994) A desktop guide for the management of non-insulin dependent diabetes. D iabet M ed 11: 899-909

28. Treasure CB, K lein J L, Weintraub W S, et al. (1995) B eneficial effects of cholesterol-lowering therapy on the coronary 
endothelium in patients with coronary artery disease. N Engl J Med 332: 481-487

29. Davda RK, Stepniakowski KT, Lu G, Ullian ME, Goodfriend TL, E gan BM (1995) O leic acid inhibits endothelial nitric oxide synthase by a protein kinase $\mathrm{C}$-independent mechanism. $H$ ypertension 26: 764-770

30. Steinberg H O, Chaker H, L eaming R, J ohnson A, B rechtel G, Baron A D (1996) O besity/insulin resistance is associated with endothelial dysfunction. J Clin invest 97: 26012610

31. Steinberg H O, B rechtel G, Johnson A, Fineberg N, Baron A D (1994) Insulin-mediated skeletal muscle vasodilation is nitric oxide dependent. J Clin Invest 94: 1172-1179

32. Trovati $M, M$ assucco $P, M$ attiello $L$ et al. (1995) I nsulin increases cyclic nucleotide content in human vascular smooth muscle cells: a mechanism potentially involved in insulininduced modulation of vascular tone. Diabetologia 38 : 936-941

33. L aakso M, E delman SV, B rechtel G, B aron A D (1992) Impaired insulin-mediated skeletal muscle blood flow in patients with NIDD M . D iabetes 41: 1076-1083
34. M cVeigh GE , B rennan G M , J ohnston G D et al. (1992) Impaired endothelium-dependent and independent vasodilation in patients with type 2 (non-insulin-dependent) diabetes mellitus. D iabetologia 53: 771-776

35. Morris SJ, Shore A C, Tooke JE (1995) R esponses of the skin microcirculation to acetylcholine and sodium nitroprusside in patients with NIDD M. D iabetologia 38: 13371344

36. Ferri C, Carlomagno A, Coassin S et al. (1995) Circulating endothelin-1 levels increase during euglycaemic hyperinsulinaemic clamp in lean NIDDM men. Diabetes Care 18: 226-233

37. N ugent A G, M cG urk C, H ayes J R, Johnston GD (1996) Impaired vasoconstriction to endothelin-1 in patients with NIDD M . D iabetes 45: 105-107

38. Taggart H, Stout RW (1980) Control of D NA synthesis in cultured vascular endothelial and smooth muscle cells. A therosclerosis 37: 549-557 